Matthew D. Shapiro is professor of economics at the University of Michigan and research associate at the National Bureau of Economic Research. David W. Wilcox is senior economist at the Board of Governors of the Federal Reserve System. They are grateful to Brent Moulton, Marshall Reinsdorf, and Erwin Diewert for comments on an earlier draft; to Dwight Bibbs for excellent research assistance; to the Bureau of Labor Statistics for compiling the data set; and to Anna Aizcorbe, Patrick Jackman, and Robert Cage for discussion of the data and related issues. Shapiro acknowledges the financial support of the Alfred P. Sloan Foundation.

\section{Alternative Strategies for Aggregating Prices in the CPI}

\section{Matthew D. Shapiro and David W. Wilcox}

growing body of evidence suggests that the consumer price index (CPI) overstates the true rate of increase in the cost of living. One of the best-understood and best-documented sources of bias in the CPI as a measure of the cost of living is its failure to take into account that consumers alter the composition of their purchases in response to changes in relative prices. In our recent examination of the evidence on biases in the CPI, we labeled the bias arising from this failure the "across-strata" effect. ${ }^{1}$

In contrast to the CPI, members of the so-called superlative class of price indexes do allow for substitution among goods and services in response to changes in relative prices. Given certain assumptions, superlative indexes can be shown to provide second-order approximations to the true cost-of-living index, ${ }^{2}$ whereas fixed-weight indexes, including the Laspeyres index, provide only first-order approximations. This difference in degree of approximation has led many researchers (including us) to interpret the discrepancy between a Laspeyres-type index and a superlative index as an estimate of the across-strata effect in the CPI.

The Bureau of Labor Statistics (BLS) has taken many steps through the years to improve the CPI. Of the various remaining sources of bias in the $\mathrm{CPI}$ as a measure of the cost of living, the across- strata effect is probably the easiest to address. To borrow a phrase from Vice President Gore's National Performance Review, the across-strata effect is the "low-hanging fruit" of the remaining CPI biases, because the economic theory of superlative prices indexes is well understood, and relevant data on prices and quantities are available.

This article has two major purposes. The first purpose is to present a new estimate of the magnitude of the across-strata effect in the CPI. The new estimate differs from its predecessors in two key respects. First, it is derived from a new data set recently constructed at our request and released by BLS. As we discuss, the new data set builds on the pioneering work of Aizcorbe and Jackman (1993). ${ }^{3}$ Second, the new estimate is derived from a direct comparison between the $\mathrm{CPI}$ itself and its superlative counterparts: Previous researchers used either a 1982-based or a 1986-based Laspeyres-type index in place of the $\mathrm{CPI}$ and assumed that the results were relevant for the CPI, which is calculated using expenditure shares from the threeyear period 1982-84. We find a noticeable difference between the actual CPI and either the 1982-based or the 1986-based Laspeyres index. This difference leads us to conclude that the across-strata effect between 1986 and 1995 was somewhat larger than earlier researchers have believed.

The second major purpose of this article is to propose a method for picking the lowhanging fruit- that is, for publishing a realtime index substantially free of across-strata bias. In doing so, we confront-and propose resolutions of- two practical difficulties.

First, the data on expenditures required for computation of either Fisher's I deal index or the Törnqvist index are available only at the quarterly frequency. Moreover, the sample size in the underlying survey is such that considerable averaging across quarters is required before the resulting estimates of expenditure shares at the stra-
The views expressed in this article are those of the authors; they are not necessarily shared by the members of the Board of Governors of the Federal Reserve System, nor by the other members of its staff.

1 See Shapiro and Wilcox (1996a). A "stratum" in the CPI is an item-area pair ( $e . g_{1}$, apples in St. Louis or dental services in Denver). We refer to the effect arising from substitution among goods and services as "across" strata to distinguish it from the substitution within strata (e.g., among stores selling apples). Our best guess is that the across-strata and the within-strata biases are independent of each other. See also Shapiro and Wilcox (1996b).

2 See Diewert (1976).

3 The new data set was constructed by Robert Cage of the BLS. 
tum level are deemed sufficiently reliable to be used in the CPI. Indeed, the BLS currently calculates the aggregation weights in the CPI using three years' worth of expenditures data. The unavailability of monthly data on expenditures implies that neither the Törnqvist index nor Fisher's Ideal index can be implemented exactly, even retrospectively.

The second major difficulty we confront is that the relevant data on expenditures become available only after a lag of about 9 or 10 months. This implies that the best possible approximation to a superlative index can be produced only after a lag of at least that long (possibly longer, depending on the details of any averaging of expenditure shares). The BLS could deal with this lag in data availability in any of several ways:

- Delay publication of a superlative-type index until final expenditures data are available.

- Publish a preliminary version of the superlative-type index (based on expenditures data available in real time) and make this preliminary version susceptible to revision.

- Publish two separate indexes, one using the latest available expenditures data and al ways susceptible to revision, the other using only the expenditures data available in real time and not susceptible to revision.

Boskin, et al. (1996) recommended that the BLS pursue the third option. We view our work here as helping to lay the groundwork for implementing that option.

The rest of this article is organized as follows: We review the formulas for computing price indexes, paying special attention to what is feasible to compute ( given the data currently collected); provide the new estimate of the magnitude of the across-strata effect; propose a method for alleviating the across-strata effect on a realtime basis; and discuss the implications of our findings.

\section{SUPERLATIVE PRICE INDEXES AND THE CPI IN PRACTICE}

We begin with a short, practical review of some basic price index formulas and their relationship to the $\mathrm{CPI}$. The basic ingredients of a price index are the price of item $i$ in year $y$ and month $m$, denoted $p_{i, y, m}$, and the quantity of this item purchased $q .{ }^{4}$ If price and quantity were both observed at the monthly frequency and on a timely basis, it would be straightforward to cal culate a superlative version of the CPI. As we noted earlier, however, expenditures (and, hence, quantities) are observed neither monthly nor on a timely basis. In this section, we concentrate only on the implications of the frequency of the expenditure data and consider timeliness later.

The BLS obtains information on nominal expenditures from the Consumer Expenditures Survey (CEX), which provides quarterly data. These are sufficiently noisy as to require averaging over many quarters before they can be used in the $\mathrm{CPI}$. In part, the need to average the CEX data over time reflects the current practice of producing area-specific price indexes. If, instead, a determination were made that only regional indexes or a single national index was to be produced, the need for time averaging of expenditures data might be substantially reduced. Even in the unlikely event that such a move alleviated any need for time averaging, the expenditures data would still be available only quarterly, given the current structure of the CEX. At present, the weights in the CPI are calculated using average expenditures for the three-year period from 1982 through 1984. The BLS plans to introduce new weights at the end of 1997, based on average expenditures during the three-year period from 1993 through 1995.

The mismatch in frequency between the price and expenditure data creates an ambiguity as to how one might best approximate the index formulas prescribed by theory. In constructing the CPI, the BLS deals with this problem by taking the following "modified" Laspeyres index as its statistical target for months after 
December 1986, when the 1982-84 market basket was introduced:

$$
\frac{P_{y, m}^{C P I}}{P_{1986,12}^{C P I}}=\frac{\sum_{i} q_{i, b} p_{i, y, m}}{\sum_{i} q_{i, b} p_{i, 1986,12}},
$$

where $b$ denotes the base period, currently 1982-84. Note that the CPI can be interpreted as the ratio of the cost of purchasing the base-period quantities at current-period prices to the cost of purchasing those same quantities at link-period prices. (December 1986 is referred to as the "link period" because that is when the current market basket was introduced.)

The BLS does not observe quantities, so a more accurate representation of the method it actually uses to calculate the CPI for months after December 1986 is:

$$
\begin{gathered}
\frac{P_{y, m}^{C P I}}{P_{1986,12}^{C P I}}=\frac{\sum_{i} e_{i, b} \frac{p_{i, y, m}}{p_{i, b}}}{\sum_{i} e_{i, b} \frac{p_{i, 1986,12}}{p_{i, b}}} \\
\frac{\sum_{i} e_{i, b} \frac{p_{i, 1986,12}}{p_{i, b}} \frac{p_{i, y, m}}{p_{i, 1986,12}}}{\sum_{i} e_{i, b} \frac{p_{i, 1986,12}}{p_{i, b}}}= \\
\sum_{i} R I W_{i, 1986,12} \frac{p_{i, y, m}}{p_{i, 1986,12}}
\end{gathered}
$$

where $e_{1, b}$ is the nominal expenditure devoted to item i during base period $b$, and RI $W_{i, 1986,12}$ is the "relative-importance weight" of item i in December 1986. The relative-importance weight of item i in December 1986 can be interpreted as the ratio of outlays for that item to total outlays in that month, assuming the quantities were the same then as they were in the base period.
Although the BLS measures base-period expenditures $e_{i, b}$ over a three-year period, it proxies for the base-period price, $p_{i, b}$, using the June 1983 reading on the relevant item-area price index-in other words, the reading from approximately the middle of the base period. ${ }^{5}$ If stratumlevel price indexes were easily available for the entire base period, it would make sense to identify $p_{i, b}$ with the arithmetic average of the 36 monthly readings for stratum i during the base period, rather than with any single monthly reading. Such may not have been the case, however, when the 1982-84 market basket was being introduced, because the BLS in January 1983 changed its method for measuring homeowners' costs from an asset-value-based approach to the current owners'-equival ent-rent-based approach.

Just as it is not possible with existing source data to calculate the textbook version of the Laspeyres index, so it is not possible to calculate the textbook versions of either Fisher's I deal index, the Törnqvist index, or a geometric-means index. Following Aizcorbe and Jackman (1993), we calculate chained versions of the two superlative indexes, with the links in the chain occurring each December. Specifically, we calculate the growth of a Fisher's-I dealtype index from December in year $y-1$ to month $m$ in year $y$ as the geometric mean of the growth of a Laspeyres-type index based in December of year $y-1$ and a Paasche-type index based in December of year $y$ :

(2) $\frac{P_{y, m}^{F}}{P_{y-1,12}^{F}}=\left(\frac{P_{y, m}^{L}}{P_{y-1,12}^{L}} \cdot \frac{P_{y, 12}^{P} / P_{y-1,12}^{P}}{P_{y, 12}^{P} / P_{y, m}^{P}}\right)^{1 / 2}$.

The representation of the growth of the Paasche index is necessarily cluttered because neither December of year $y-1$ nor month $m$ of year $y$ is the base period for the index (unless $m$ happens to be December).

The formula for the Laspeyres-type $\quad{ }^{5}$ See Bureau of Labor Statistics index is given by:
5 See Bureau of Labor Statistics
(1992), p. 180. 
${ }^{6}$ We are grateful to Brent Moulton for bringing the evidence in Braithwait to our attention.
(3)

$$
\frac{P_{y, m}^{L}}{P_{y-1,12}^{L}}=\sum_{i} \omega_{i, y-1} \frac{p_{i, y, m}}{p_{i, y-1,12}},
$$

where $\omega_{i, y-1}$ is the expenditure share of stratum $i$ in year $y-1$. Similarly, the formula for the Paasche-type index is given by:

$$
\frac{P_{y, 12}^{P}}{P_{y, m}^{P}}=\left(\sum_{i} \omega_{i, y} \frac{p_{i, y, m}}{p_{i, y, 12}}\right)^{-1},
$$

where $\omega_{i, y}$ is the share of expenditures falling on stratum $i$ in year $y$.

Equations 2, 3, and 4 follow Aizcorbe and Jackman (1993) insofar as calculation of December-to-December changes are concerned. But these equations go beyond Aizcorbe and Jackman in proposing a specific method for calculating a Fisher-type index at the monthly frequency. The method we propose could be further refined by (a) centering the price relatives within the period during which the expenditure shares are calculated (e.g., by measuring the price in the denominator on the right side of Equation 3 as the arithmetic average of the June and July values for stratum i in year $y-1)$, and (b) updating (and "downdating") the expenditure shares to the period during which the denominators of the price relatives are measured. A further possible refinement might use appropriately aligned quarterly expenditures data. We have limited ourselves here to use of expenditures data at the annual frequency. follows:

We compute a Törnqvist-type index as

$$
\text { (5) } \frac{P_{y, m}^{T}}{P_{y-1,12}^{T}}=\prod_{i}\left(\frac{p_{i, y, m}}{p_{i, y-1,12}}\right)^{\frac{\omega_{i, y-1}+\omega_{i, y}}{2}} \text {. }
$$

This index is calculated as the weight-

index could also be refined by centering the denominators of the price relatives within the period during which expenditure shares are calculated. We doubt that updating of expenditure shares is appropriate in the case of the Törnqvist index and have not performed any updating here.

Finally, we calculate a fixed-base geometric-means price index as:

$$
\frac{P_{y, m}^{G}}{P_{y_{0}, 12}^{G}}=\prod_{i}\left(\frac{p_{i, y, m}}{p_{i, y_{0}, 12}}\right)^{\omega_{i, y_{0}}} .
$$

This index is exact for the cost of living if the utility of the representative consumer is given by the Cobb-Douglas function. In that case, expenditure shares are constant across time. Any averaging that might be done is therefore strictly an issue of noise reduction and does not introduce any approximation.

Previous investigators' results suggest that using the geometric-means formula to aggregate the stratum-level indexes would induce a downward bias in the overall index. For example, unpublished tables provided by the BLS and calculated from the Aizcorbe-Jackman data set show the geometric-means index growing more slowly than either the Törnqvist price index or Fisher's I deal price index. Consistent with this finding, most of the compensated ownprice elasticities shown by Braithwait (1980) are less than $1 .^{6}$

Following Aizcorbe and Jackman, we present results only for December-overDecember changes in price. We reiterate, however, that the formulas we have presented could be used to calculate results at the monthly frequency.

\section{ASSESSING THE ACROSS- STRATA EFFECT}

This section updates the work of ed geometric mean of the price relatives from December in year $y-1$ to month $m$ in year $y$, where the weights are the arithmetic averages of the expenditure shares in years $y-1$ and $y$. The calculation of this
Aizcorbe and Jackman (1993) in assessing the magnitude of the across-strata effect, using a newly assembled data set that BLS made available to us in December 1996. Aizcorbe and Jackman constructed their 
original data set relatively soon after the 1987 revision to the CPI. Although the easiest thing by far for them to have done would have been to include only post-December 1986 data in their data set, doing so would have left them with only a few years' worth of observations. Accordingly, Aizcorbe and Jackman extended the data set back to December 1982, when the BLS introduced the current rental-equivalence approach to measuring homeowners' costs. A consequence of extending the data set backward in time was that Aizcorbe and Jackman then had to deal with several discontinuities introduced with the 1987 revision. For example, the previously unified N ew York metropolitan area was divided into three areas, and a new item was introduced for information-processing equipment. Aizcorbe and Jackman handled these situations by painstakingly constructing three concordances linking the pre- and post-1987 data.

In comparison with the original Aizcorbe and Jackman data set, the new one is conceptually straightforward because it includes only post-December1986 data. The new data set contains 9,522 monthly time series on price relatives-one for each possible combination of 46 areas and 207 items. For reasons explained in the Appendix, we consolidate four of these areas into two. The version of the data set we use, therefore, has 9,108 monthly time series on prices. This data set was merged with corresponding annual data from the CEX on expenditures.

\section{Retrospective Estimates of the Across-Strata Effect}

The top panel of Table 1 (next page) shows December-over-December rates of price change, calculated according to a variety of different methods. These estimates could not have been calculated in real time. Later in this article, we address the problem of ameliorating the across-strata effect in real time.

The first column in the top panel of Table 1 shows inflation as measured using the CPI aggregation formula and the official CPI weights (i.e., according to Equation 1).
The second column shows inflation as measured by a different Laspeyres-type aggregator, this one based on expenditure shares for 1986. The third column shows the Fisher index (Equation 2), while the fourth shows the Törnqvist index (Equation 5). The fifth column shows the index based on geometric means (Equation 6). The bottom panel gives the differences of the non-CPI indexes from the CPI. In both the top and bottom panels, the last two rows give the means and standard deviations of the annual figures.

The difference between either the Törnqvist or Fisher measure of price growth and the CPI represents an estimate of the across-strata effect in the CPI. Between 1987 and 1995, the across-strata effect by either measure averaged an estimated 0.30 percentage point per year, with a standard deviation of 0.12 percentage point per year.

These results cause us to boost our estimate of the average magnitude of the across-strata effect between December 1986 and December 1995 to 0.3 percentage point per year. ${ }^{7}$ Looking prospectively, however, our best guess remains that the across-strata effect will average about 0.2 percentage point per year once the updated market basket based on expenditure shares for 1993-95 is introduced. This estimate is based on the 1986-based Laspeyres index shown in the second column of Table 1, which increases about 0.2 percentage point per year faster than the Törnqvist index. ${ }^{8}$ Our best guess is that the difference between the CPI and the Laspeyres index reported in Table 1 occurs because of idiosyncrasies in the 1982-84 weights, which may not be replicated in the 1993-95 weights.

We see little evidence linking the magnitude of the across-strata effect to the age of the market basket. Accordingly, we are not particularly optimistic that updating the market basket every 5 years rather than every 10 years would noticeably reduce the average magnitude of the across-strata effect. In any event, the solution for the across-strata effect seems to us clearly to involve moving away from a fixed-market basket concept, not a more rapid turnover of the market basket.
7 In Shapiro and Wilcox (1996a), we used an updated version of the original AizcorbeJackman data set, and estimated the across-strata effect at 0.2 of a percentage point per year. This result was consistent with the finding of Aizcorbe and Jackman in their 1993 article. These estimates were calculated using a 1982-based Laspeyres index rather than the official CPI.

${ }^{8}$ Laspeyres indexes with base years later than 1986 also exhibit about the same differences from the Törnqvist. 


\section{Table 1}

\section{Alternative Measures of Annual Inflation and Alternative Estimates of the Across-Strata Effect*}

\begin{tabular}{|c|c|c|c|c|c|}
\hline Year & $\mathrm{CPI}^{\dagger}$ & Laspey res $^{\dagger}$ & Fisher & Törnqvist & Geometric \\
\hline 1987 & 4.44 & 4.54 & 4.27 & 4.27 & 4.22 \\
\hline 1988 & 4.41 & 4.25 & 4.05 & 4.07 & 4.04 \\
\hline 1989 & 4.65 & 4.43 & 4.21 & 4.21 & 4.20 \\
\hline 1990 & 6.16 & 6.05 & 5.64 & 5.63 & 5.49 \\
\hline 1991 & 3.00 & 2.61 & 2.77 & 2.77 & 2.58 \\
\hline 1992 & 2.96 & 2.78 & 2.61 & 2.61 & 2.46 \\
\hline 1993 & 2.74 & 2.57 & 2.45 & 2.45 & 2.27 \\
\hline 1994 & 2.65 & 2.72 & 2.54 & 2.54 & 2.52 \\
\hline 1995 & 2.57 & 2.39 & 2.32 & 2.32 & 2.13 \\
\hline $\begin{array}{l}\text { Mean } \\
\text { Std. dev. }\end{array}$ & $\begin{array}{l}3.73 \\
1.17\end{array}$ & $\begin{array}{l}3.59 \\
1.20\end{array}$ & $\begin{array}{l}3.43 \\
1.09\end{array}$ & $\begin{array}{l}3.43 \\
1.09\end{array}$ & $\begin{array}{l}3.32 \\
1.12\end{array}$ \\
\hline
\end{tabular}

Differences from CPI

\begin{tabular}{|l|l|l|l|l|}
\hline 1987 & -0.10 & 0.17 & 0.17 & 0.23 \\
\hline 1988 & 0.16 & 0.36 & 0.34 & 0.37 \\
\hline 1989 & 0.21 & 0.43 & 0.43 & 0.45 \\
\hline 1990 & 0.11 & 0.51 & 0.53 & 0.67 \\
\hline 1991 & 0.39 & 0.24 & 0.24 & 0.42 \\
\hline 1992 & 0.18 & 0.35 & 0.35 & 0.50 \\
\hline 1993 & 0.17 & 0.29 & 0.29 & 0.47 \\
\hline 1994 & -0.07 & 0.12 & 0.12 & 0.13 \\
\hline 1995 & 0.18 & 0.25 & 0.25 & 0.44 \\
\hline Mean & 0.14 & 0.30 & 0.30 & 0.41 \\
\hline Std. dev. & 0.14 & 0.12 & 0.12 & 0.15 \\
\hline
\end{tabular}

* Percentage points per year.

${ }^{\dagger}$ Expenditure shares measured in 1982-84 and updated for relative price change to the end of 1986.

¥ Expenditure shares measured in 1986.

As we have noted, the geometric-means index provides an estimate of the cost of living for a Cobb-Douglas representative consumer. As expected, the geometric price index increases less rapidly than does either the Törnqvist index or Fisher's I deal index. In other words, the unit elasticity of substitution implicit in the geometric formula appears to overstate the extent to which consumers respond to changes in relative prices at the upper level of aggregation.

Before concluding this section, we digress briefly to consider how well we can explain the year-to-year variation in the across-strata effect. In particular, we would like to be able to explain whycontrary to widespread presumption - the across-strata effect does not exhibit any 


\section{Figure 1}

\section{Across-Strata Effect and Pace of Relative Price Drift}

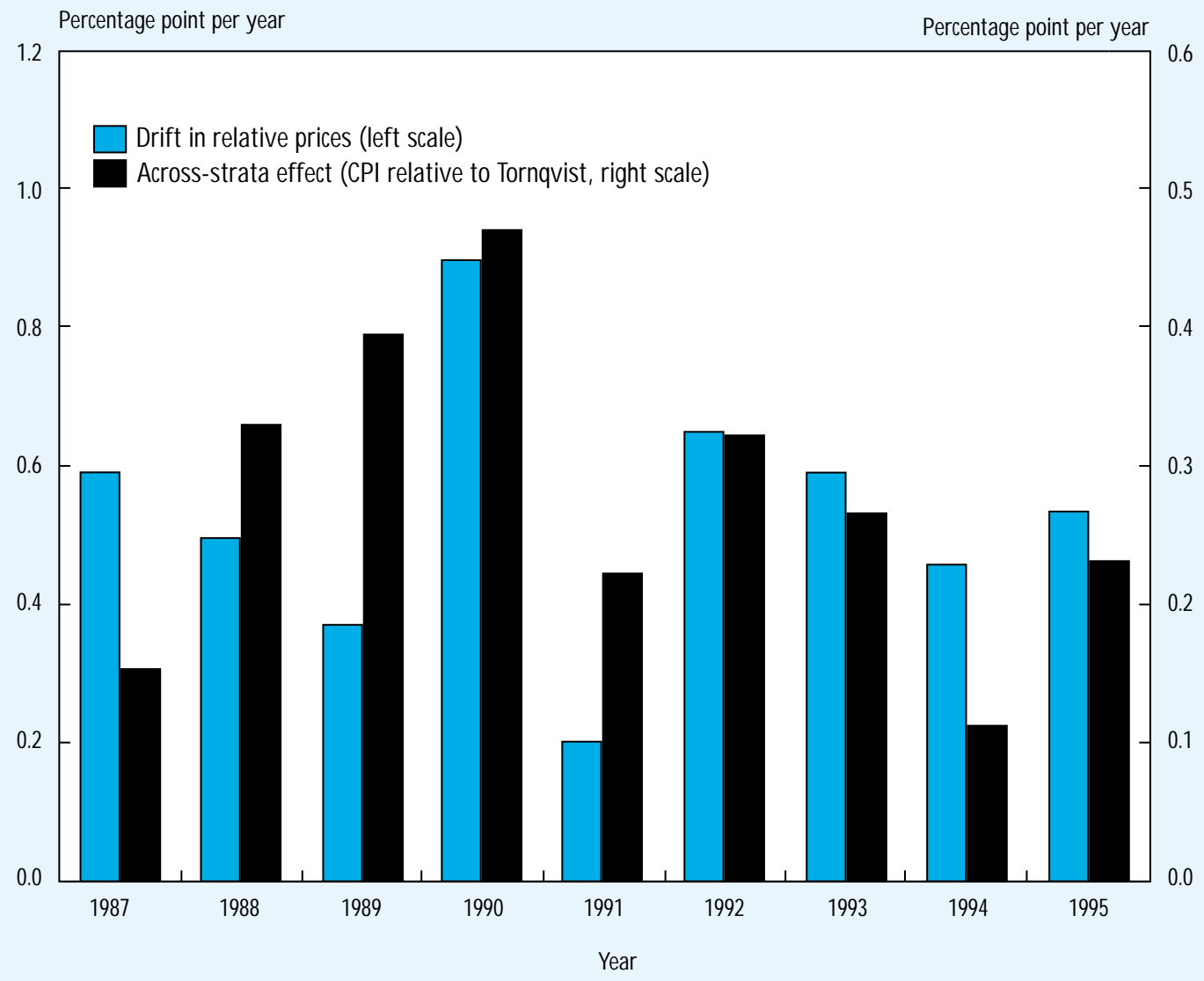

tendency to increase in size as the market basket becomes more outdated. One possible explanation for the absence of any trend along these lines is that inflation declined during the period studied here. If the decline in inflation was associated with a reduction in the variability of relative prices, consumers might have had less scope for substitution later in the sample period. We tested this hypothesis by constructing an index of the cumulative change in relative prices, as follows:

$$
\begin{gathered}
J_{y, m}=\sum_{i} R I W_{i, 1986,12} \\
\left|\ln \left(\frac{p_{i, y, m}}{p_{i, 1986,12}}\right)-\ln \left(\frac{P_{y, m}^{G^{*}}}{P_{1986,12}^{G^{*}}}\right)\right|
\end{gathered}
$$

Thus, $J_{y, m}$ is an index of cumulative relative price change since December 1986, when the current market basket in the CPI was introduced. As in Equation 1', RIW denotes the official CPI relativeimportance weights as of December 1986. The aggregate index $\mathrm{P}_{\mathrm{y}, \mathrm{m}}^{*} / \mathrm{P}_{1986,12}^{*}$ is calculated according to Equation 6, substituting the official relative importance weights for the 1986 expenditure shares.

The index $J_{y, m}$ would equal zero if no net change in relative price had taken place since December 1986. A decline in the value of $J$ (from a positive level) would indicate that relative prices had moved back more into line with their constellation as of December 1986.

The scope for substitution in any given year should be a function of the drift in relative prices during that year. 
Alternative Measures of Inflation*

\begin{tabular}{|c|c|c|c|c|c|c|}
\hline \multirow[b]{2}{*}{ Year } & \multicolumn{2}{|c|}{$\begin{array}{l}\text { Substitutability Across Areas } \\
\text { Not Restricted to Zero }\end{array}$} & \multicolumn{2}{|c|}{$\begin{array}{c}\text { Zero Substitutability Across } \\
\text { Areas }\end{array}$} & \multicolumn{2}{|c|}{ Difference } \\
\hline & Törnqvist & Geometric & Törnqvist & Geometric & Törnqvist & Geometric \\
\hline 1987 & 4.268 & 4.215 & 4.272 & 4.220 & 0.004 & 0.005 \\
\hline 1988 & 4.068 & 4.040 & 4.066 & 4.046 & -0.002 & 0.007 \\
\hline 1989 & 4.213 & 4.198 & 4.211 & 4.208 & -0.002 & 0.010 \\
\hline 1990 & 5.629 & 5.488 & 5.636 & 5.494 & 0.007 & 0.006 \\
\hline 1991 & 2.766 & 2.580 & 2.764 & 2.588 & -0.002 & 0.008 \\
\hline 1992 & 2.605 & 2.456 & 2.615 & 2.462 & 0.010 & 0.007 \\
\hline 1993 & 2.445 & 2.270 & 2.446 & 2.267 & 0.001 & -0.003 \\
\hline 1994 & 2.535 & 2.521 & 2.542 & 2.514 & 0.007 & -0.006 \\
\hline 1995 & 2.324 & 2.132 & 2.320 & 2.134 & -0.004 & 0.002 \\
\hline Mean & 3.428 & 3.322 & 3.430 & 3.326 & 0.002 & 0.004 \\
\hline Std. dev. & 1.089 & 1.117 & 1.090 & 1.120 & 0.005 & 0.005 \\
\hline
\end{tabular}

*Percentage points per year calculated under the assumption of zero substitution across areas.

Accordingly, we compare the Decemberto-December changes in $J$ to the estimates of the across-strata effect derived by comparing the CPI to the Törnqvist index. The results are shown in Figure 1 on the previous page. We see these results as mixed: Beginning in 1989, our index of relative price change appears to have some explanatory power for the size of the acrossstrata effect. Still, the first three years remain a puzzle: There, the pace of relative price drift was declining, but the size of the across-strata effect was increasing.

\section{Imposing a Zero Elasticity of Substitution Across Areas}

The price index calculations reported in Table 1 assume that consumers may substitute any item-area stratum in the CPI market basket for any other. In this section, we contemplate placing restrictions on the allowable range of substitution. In particular, we explore the implications of imposing the restriction that the elasticity of substitu- tion across areas is zero. The results just presented strongly suggest that the elasticity of substitution among at least some CPI item-area strata is not zero. But we believe it likely that the evident sensitivity to relative price changes arises from substitution across strata within areas, not across areas. Indeed, the CPI's assumption of zero elasticity of substitution across areas strikes us as more plausible than the geometric-means index's assumption of a unit elasticity of substitution across areas, as well as across items within areas. Moreover, although the Törnqvist index will handle the case of zero elasticity of substitution, there might be a case for imposing it to reduce the impact of noise in the estimated expenditure shares.

Table 2 shows the effect of imposing a zero elasticity of substitution across areas. The first two columns repeat the results for the Törnqvist and geometric indexes from Table 1, with one extra decimal point of precision. The next two columns show the results we obtain 
when we rule out the possibility of substitution across areas. Specifically, we apply the Törnqvist and geometric indexes within areas and then aggregate the area-level indexes using the Laspeyres formula based on 1986 weights. The last two columns give the differences between the restricted and unrestricted estimates.

The differences between the unrestricted and restricted versions of the Törnqvist index are very small. Indeed, at first glance, this result appears to be a powerful victory for superlative index numbers: The standard Törnqvist index appears to be capable of tracking zeroelasticity behavior remarkably well.

But the geometric index also differs little when a zero elasticity of substitution across areas is imposed. Given that the geometric index assumes a unit elasticity, we would have expected a more substantial difference if relative price variation across areas were substantial. Hence, Table 2 may be best interpreted as showing that relative price variation across areas is insubstantial, in which case there would be little bite to imposing a zero el asticity. ${ }^{9}$

We also tried inverting the order of operations involved in imposing the zeroelasticity index. Specifically, we tried applying the Laspeyres aggregator across areas first, and then applying the Törnqvist aggregator across items. The resulting index can be interpreted as a "national" version of the $C P I$ because it treats the entire country as one area. (A true national index would be based on a probability sample drawn for that purpose.) This index increased about 0.2 percentage point per year faster, on average, between December 1986 and December 1995 than did the standard Törnqvist index. That the "national" index grows more quickly is a consequence of Jensen's inequal ity. Our results suggest that research on appropriate national sampling weights is required before the Boskin Commission's (1996) recommendation that some items be priced on a national basis could be implemented.

\section{REAL-TIME FEASIBLE PRICE INDEXES}

Using the Törnqvist or Fisher indexes presented in the previous section, one can estimate an index free of the across-strata effect currently afflicting the CPI. But owing to delays in the availability of the required expenditures data, these superlative indexes cannot be computed on as timely a basis as is possible with the current $\mathrm{CPI}$. In this section, we explore the performance of an alternative index formula implementable in real time.

Our aim is to produce an approximation of the Törnqvist index that can be computed using the data available to the $\mathrm{BLS}$ when it assembles the CPI. The BLS has the price relatives with a lag of less than one month, but the expenditure shares for year $y$ are not available until about September or October of year $y+1$.

The evidence presented in the previous section suggests that the $\mathrm{CPI}-\mathrm{a}$ Laspeyres-type index-grows more quickly than either the Törnqvist index or Fisher's Ideal index; however, an index based on geometric means grows more slowly. Accordingly, we look for an intermediate case from within the family of utility functions that exhibit a constant elasticity of substitution (CES) across items. ${ }^{10}$

We construct the real-time index as follows:

(8)

$$
\frac{P_{y, m}^{R T}}{P_{y-1,12}^{R T}}=\frac{P_{y, m}^{C E S} / P_{y-2,12}^{C E S}}{P_{y-1,12}^{C E S} / P_{y-2,12}^{C E S}} .
$$

We calculate the numerator of Equation 8 as follows:

(9)

$$
\frac{P_{y, m}^{C E S}}{P_{y-2,12}^{C E S}}=\left[\sum_{i} \omega_{i, y-2}\left(\frac{p_{i, y, m}}{p_{i, y-2,12}}\right)^{1-\sigma}\right]^{1 /(1-\sigma)},
$$

where $\sigma$ is the elasticity of substitution between items (assumed to be identical for all possible pairs of goods). Because we use expenditure shares from year $y-2$, and those expenditure shares are avail-
9 Two of the differences for the geometric means estimator are negative. If the estimator were chained, this would not be possible. However, because we use a fixed-base estimator, there is no restriction on the sign of the difference.

${ }^{10}$ We are grateful to Brent Moulton for suggesting that we investigate the CES family of utility functions as the basis for a real-time index. 


\section{Table 3}

\section{Alternative Estimates of the Rate of Change in the Cost of Living*}

\begin{tabular}{|c|c|c|c|c|c|}
\hline \multirow[b]{2}{*}{ Year } & \multirow[b]{2}{*}{$\mathrm{CPI}$} & \multicolumn{3}{|c|}{ CES } & \multirow[b]{2}{*}{ Törnquist } \\
\hline & & $\sigma=.6$ & $\sigma=.7$ & $\sigma=.8$ & \\
\hline 1988 & 4.41 & 4.13 & 4.11 & 4.09 & 4.07 \\
\hline 1989 & 4.65 & 4.23 & 4.21 & 4.19 & 4.21 \\
\hline 1990 & 6.16 & 5.63 & 5.58 & 5.54 & 5.63 \\
\hline 1991 & 3.00 & 2.68 & 2.68 & 2.67 & 2.77 \\
\hline 1992 & 2.96 & 2.64 & 2.61 & 2.58 & 2.61 \\
\hline 1993 & 2.74 & 2.51 & 2.49 & 2.46 & 2.45 \\
\hline 1994 & 2.65 & 2.59 & 2.58 & 2.56 & 2.54 \\
\hline 1995 & 2.57 & 2.36 & 2.35 & 2.33 & 2.32 \\
\hline $\begin{array}{l}\text { Mean } \\
\text { Std. dev. }\end{array}$ & $\begin{array}{l}3.64 \\
1.21\end{array}$ & $\begin{array}{l}3.35 \\
1.11\end{array}$ & $\begin{array}{l}3.32 \\
1.10\end{array}$ & $\begin{array}{l}3.30 \\
1.09\end{array}$ & $\begin{array}{l}3.32 \\
1.11\end{array}$ \\
\hline
\end{tabular}

Differences from Törnqvist

\begin{tabular}{|l|l|l|l|r|}
\hline 1988 & 0.34 & 0.06 & 0.04 & 0.02 \\
\hline 1989 & 0.43 & 0.02 & -0.00 & -0.02 \\
\hline 1990 & 0.53 & -0.00 & -0.05 & -0.09 \\
\hline 1991 & 0.24 & -0.08 & -0.09 & -0.09 \\
\hline 1992 & 0.35 & 0.03 & 0.00 & -0.02 \\
\hline 1993 & 0.29 & 0.07 & 0.04 & 0.02 \\
\hline 1994 & 0.12 & 0.06 & 0.04 & 0.02 \\
\hline 1995 & 0.25 & 0.04 & 0.02 & 0.01 \\
\hline Mean & 0.32 & 0.02 & 0.00 & -0.02 \\
\hline Std. dev. & 0.12 & 0.05 & 0.04 & 0.05 \\
\hline
\end{tabular}

* Percentage points per year. The columns headed by values of $\sigma$ report the CES index for elasticities of substitution equal to $0.6,0.7$, and 0.8 .

able by the end of year $y-1$, Equations 8 and 9 are implementable in real time, at the monthly frequency.

Lloyd (1975) and Moulton (1996) show that Equation 9 would be exact for the cost of living if the utility of the representative agent came from the CES family and if the expenditure shares were measured during the same period as the denominator of the price relatives. Just as we suggested might be done with the for- mulas presented earlier, Equation 9 might be further refined by centering the price relatives within the period during which the expenditure shares are measured. In addition, the expenditure shares could be updated to the period during which the denominator of the price relative is measured. Finally, the underlying quarterly data on expenditures could be employed.

Table 3 compares annual rates of change in the cost of living, calculated using five 
different aggregation formulas. Column 1 uses the CPI aggregation formula and weights, thus repeating the first column from Table 1. We drop the observation for 1987 because we are using lagged expenditure shares in the computation of the CES indexes. Columns 2 through 4 present the results of implementing Equations 8 and 9, for three different assumptions about the elasticity of substitution: $\sigma=0.6, \sigma=0.7$, and $\sigma=0.8$. Finally, column 5 uses the Törnqvist aggregation formula (repeating the fourth column from Table 1). The top panel of the table shows the rates of change in the various indexes, while the bottom panel shows the differences between the non-Törnqvist and Törnqvist indexes.

As we noted in the previous section, the CPI grows more rapidly than the Törnqvist. The same is true for the CES index with $\sigma$ set equal to 0.6. With $\sigma$ set equal to 0.7 , however, the average growth in the CES index is almost exactly the same as the average growth in the Törnqvist index during this period. With $\sigma$ set equal to 0.8 , the CES grows a bit too slowly. The standard deviation from zero of the discrepancy between the CES (with $\sigma$ equal to 0.7 ) and the Törnqvist is 0.04 percentage point per year. Assuming these discrepancies are distributed normally, 90 percent of them should lie between -0.07 percentage point per year and 0.07 percentage point per year. In fact, with only one exception, all discrepancies are 0.05 percentage point per year or smaller in absolute value. By way of comparison, we note that the smallest discrepancy for the $\mathrm{CPI}$ aggregator is 0.12 percentage point per year, and the standard deviation of the discrepancies for the CPI formula is also 0.12 percentage point per year.

These results suggest that the CES utility function can be used to substantially eliminate the across-strata effect in the CPI in real time. In common with the conventional Laspeyres and geometric-means formulas, the CES functional form we have implemented makes the strong assumption that the elasticity of substitution is the same across all pairs of items. This restriction is unlikely to hold: The elasticity of substitu- tion between chicken and beef is surely greater than the elasticity of substitution between beef and, for example, children's clothing. The approximation of equal elasticities of substitution will cause changes in the relative price of close substitutes to contribute too much to the change in the cost of living and changes in the relative price of poor substitutes to contribute too little. The elasticity of 0.7 makes such errors cancel in the sample. If the BLS were to implement a procedure like ours, it would be well-advised to monitor that such cancellation continues to occur in the future. In particular, the BLS should make adjustments to $\sigma$ so that the average difference between the index using the projected expenditure shares and the Törnqvist index (once the actual shares become available) remains close to zero.

Our calibration exercise can be viewed as involving a crude form of estimation. One way to refine the procedure would be to make the estimation explicit rather than implicit. This could be done by estimating a demand system for the items in the CPI market basket and then calculating the exact cost-of-living index for the estimated system. Indeed, we intend to pursue this approach. In effect, this effort will represent a throwback to some of the earlier literature on the substitution bias. Of course, like the earlier authors in this genre, we will have to take a stand on various issues, including the choice of functional form. $\mathrm{N}$ onetheless, this seems to us to represent a promising avenue if the goal is to create a timely price index free of the acrossstrata bias.

\section{DISCUSSION}

One of the aims of this article is to explore the practicalities of computing a timely price index that does not suffer from systematic across-strata bias. Lags in availability of expenditure data make superlative price indexes feasible only after a certain passage of time. The results of the previous section show it is possible to produce an approximation to the Törnqvist index that is both feasible in real time and quite accurate. 
A number of issues deserve further exploration. First, we have only looked at year-to-year inflation rates, but month-tomonth rates are of great interest as well. Although we have not examined monthly data, we give a formula for an approximation to the cost-of-living index that can be implemented in real time (i.e., with the same timeliness as the CPI is now published). Second, in our consideration of annual inflation rates, it made sense to use calendar-year expenditure shares. The underlying expenditure data, however, are available on a quarterly basis. A more refined procedure than the one we have proposed here might be based on a moving average of four quarters' worth of data. The empirical properties of an index constructed along these lines should be investigated. Moreover, it is not obvious that four quarters is the optimal span of time during which to average the expenditure data. The trade-offs involved with shorter and longer periods of averaging should be explored. Third, it would be useful to develop an al gorithm for updating the elasticity of substitution in the context of the formula we propose for a real-time index. It would be useful as well to test that algorithm in Monte Carlo simulation to see, for example, how quickly the statistical agency is likely to be able to identify a change in the elasticity of substitution and change the assumed parameter value accordingly.

We have intentionally hamstrung our analysis by accepting the CPI's current item-area structure. In particular, the CPI's area structure requires a substantially richer data set than is needed to produce a national price index. Although area-level indexes might be useful for some purposes, they need not be the building blocks of a national index. It is worthwhile to investigate the building of a CPI from national indexes of the component goods and services. Indeed, with a national index, it might be possible to use other sources (e.g., the Retail Trade Survey) to develop more timely estimates of expenditure shares than the CEX provides.

Finally, some elusive empirical puzzles remain. Why is there not a more pro- nounced tendency for the estimates of the across-strata effect to drift up as the base period grows more remote? The failure of this to occur is all the more puzzling since it seems to have been a prominent feature of various price indexes in the national income and product accounts before those indexes were shifted to a Fisher's I deal basis. Also, why does imposing zero elasticity of substitution across areas make so little difference in the estimated rate of growth of the cost of living? These remaining puzzles demonstrate a need for more research in this most thoroughly examined area of CPI bias.

\section{REFERENCES}

Aizcorbe, Ana M., and Patrick C. Jackman. "The Commodity Substitution Effect in CPI Data, 1982-1991: Anatomy of Price Change," Monthly Labor Review (December 1993), pp. 25-33.

Boskin, Michael J., Ellen R. Dulberger, Robert J. Gordon, Zvi Griliches, and Dale Jorgensen. "Toward a More Accurate Measure of the Cost of Living: Final Report to the Senate Finance Committee from the Advisory Commission to Study the Consumer Price Index," U.S. Senate Finance Committee, December 1996.

Braithwait, Steven D. "The Substitution Bias of the Laspeyres Price Index: An Analysis Using Estimated Cost-of-Living Indexes," The American Economic Review (March 1980), pp. 64-77.

Bureau of Labor Statistics. "Chapter 19, The Consumer Price Index," The BLS Handbook of Methods, U.S. Government Printing Office, September 1992, pp. 176-235.

Diewert, W. Erwin. "Exact and Superlative Index Numbers," Journal of Econometrics (May 1976), pp. 115-45.

Lloyd, P.. " Substitution Effects and Biases in Nontrue Price Indices," The American Economic Review (June 1975), pp. 301-13.

Moulton, Brent R. "Constant Elasticity Cost-of-Living Index in ShareRelative Form," unpublished manuscript, Bureau of Labor Statistics, 1996.

Shapiro, Matthew D., and David W. Wilcox. "Mismeasurement in the Consumer Price Index: An Evaluation," NBER Macroeconomics Annual, Vol. 11, 1996a, pp. 93-142.

and "Generating Non-Standard Multivariate Distributions with an Application to Mismeasurement in the CPI," NBER technical working paper No. 196, May 1996b. 


\section{DATA SET}

Robert Cage of the BLS prepared the data set that forms the basis for this article. The data set was made available to us in December 1996. It includes monthly price indexes for 9,522 item-area strata ( 46 areas and 207 items), annual expenditures by stratum, and official CPI relative-importance weights as of December 1986 by stratum. (See page 111 for the definition of a relativeimportance weight).

We modified the data set in the following manner. First, we identified and adjusted four outliers in the price data set, all having to do with rebates of utility charges. Three of these pertained to natural gas charges (area 17, A pril 1990; area 45, July 1990; and area 45, March 1992). In these cases, a rebate from the natural gas utility to its customers was sufficiently large as to nearly offset the typical customer's normal monthly bill. The BLS interpreted this as implying that the "price" for the month had been nearly zero. We interpret the "price" for the month to be the marginal cost of a unit of natural gas, which remained positive. (If anything, the rebates reflected news about the marginal cost in some previous month or months.) Lacking any measure of this marginal cost, we impute in all three cases, using the reading from the preceding month. The same situation arises once with respect to local phone services (area 16, December 1989). Only the phone observation is relevant for our results in this article, because we use only December price readings.

The second modification we made to the data set was to consolidate the data for Columbus, Ohio and Milwaukee, Wisconsin, and likewise for Phoenix, Arizona and Portland, Oregon. When the 1982-84 weights were originally introduced in 1987, the BLS was collecting prices in 46 areas, including Columbus and Phoenix. Budgetary pressures forced BLS, however, to reduce its coverage from 46 areas to 44 , so it ceased collecting price and expenditures data in Columbus and Phoenix. To maintain representation of those cities in the official index, BLS increased the weight given to price changes observed in Milwaukee and Portland. To work with a uniform panel, we effectively extended this imputation procedure backward from the spring of 1988 to the beginning of the data set. We implemented this modification by attributing the sum of the expenditures shown in the data set for Columbus and Milwaukee to Milwaukee and dropped Columbus from the data set. Similarly, we attributed the sum of the expenditures shown for Phoenix and Portland to Portland and dropped Phoenix. 